\title{
Inappropriate Secretion of Thyroid Stimulating Hormone in a Filipino Patient with a Pituitary Macroadenoma
}

\author{
Lermah S. Bunoy* and Juan Maria Ibarra O. Co ${ }^{* *}$ \\ *Fellow, Section of Endocrinology, Diabetes and Metabolism, St. Luke's Medical Center, Philippines \\ ${ }^{* *}$ Consultant, Section of Endocrinology, Diabetes and Metabolism, St. Luke's Medical Center, Philippines
}

\begin{abstract}
Pituitary tumors producing thyrotropin are very rare. We report a case of a 38-year-old, male admitted for seizure, preceded by 1 week history of generalized weakness, fatigue, anorexia, nausea and vomiting, with a 5 year history of recurrent headache followed by blurring of vision, who was found to have persistently elevated serum free thyroid hormones and non-suppressed thyroid stimulating hormone (TSH) levels, with tumor residual after craniotomy with excision of the pituitary macroadenoma. To our knowledge, this is the first reported case of TSH-producing adenoma in the Philippines.
\end{abstract}

Keywords: pituitary macroadenoma, thyroid stimulating hormone, TSH-producing adenoma

\section{Introduction}

TSH-producing pituitary adenomas (TSHomas) are a rare cause of hyperthyroidism accounting for less than $1 \%$ of all cases of hyperthyroidism and $1 \%$ of all functioning pituitary tumors. ${ }^{1}$ Most patients present with classical symptoms of hyperthyroidism and few may have some or no symptoms at all. Combination of high or inappropriately normal TSH, high serum total and free thyroxine (T4) and triiodothyronine (T3), high concentration of $\alpha$-subunit, and a pituitary tumor strongly confirmed the diagnosis of a TSHoma. ${ }^{2}$.

We report a case of a 38-year-old male with persistently elevated serum free thyroid hormones and nonsuppressed TSH levels, with tumor residual after craniotomy with excision of a pituitary macroadenoma. To our knowledge, this is the first reported case of TSHoma in the Philippines.

\section{Case report}

A 38-year-old male presented in another institution because of generalized seizure lasting for 2 minutes. A week prior to the event, the patient complained of generalized weakness, fatigue, anorexia, nausea and vomiting. For the past 5 years, he claimed intermittent episodes of frontal headaches which were later associated with blurring of vision especially at the right lateral area 2 years ago. At the emergency room, the patient was initially managed as a case of adrenal insufficiency. Precluding hormonal studies, an imaging study was done. Magnetic Resonance Imaging (MRI) of the pituitary

ISSN 0857-1074

Printed in the Philippines

Copyright (C) 2012 by the JAFES

Received March 30, 2012. Accepted April 11, 2012. revealed a $4.0 \times 5.0 \times 4.5 \mathrm{~cm}$ sellar-suprasellar mass (Figure 1). Cortisol was low at $2.8 \mathrm{ug} / \mathrm{dl}$. ACTH was inappropriately normal for a low cortisol. Prolactin was within normal (Table 2). Thyroid function tests revealed elevated total hormones and elevated TSH, but repeat testing using free hormones revealed a low normal FT4 (free T4), a slightly low FT3 (free T3) and still an inappropriately elevated TSH (Table 1). Other hormonal work-ups concluded hypogonadotropic hypogonadism (Table 2). Visual field studies revealed bilateral hemianopsia. Patient was started on steroids (prednisone) and anti-seizure medication (levetiracetam). The symptoms of generalized weakness, fatigue, anorexia, nausea and vomiting resolved immediately after initiating the steroids. This confirmed concluded the diagnosis of adrenal insufficiency secondary to hypopituitarism secondary to a pituitary macroadenoma. The seizure did not recur. A repeat thyroid function test was done a month later which revealed a high normal TSH and an elevated FT4 (Table 1). However, these derangements pointing to a probable central hyperthyroidism were not taken into consideration. Patient eventually underwent craniotomy with excision of the tumor with an aggregate measurement of $3.0 \times 2.5 \times 0.5 \mathrm{~cm}$ and a pathological diagnosis of a pituitary adenoma (Figure 2a). Further excision was not possible because its consistency was firm to harn and further excision could further damage some vital tissues. Perioperative course was uneventful. Postoperative CT-scan revealed a residual mass measuring 3.1 x $4.4 \times 3.0 \mathrm{~cm}$ (Figure 3). Succeeding follow-ups were done in our institution. Patient denied recurrence of the initial symptoms except for the blurring of vision at the right lateral area, although he claimed improvement.

\footnotetext{
Corresponding author: Lermah S. Bunoy, MD

Diabetes, Thyroid and Endocrine Center

12th floor, Cathedral Heights Building

St. Luke's Medical Center

E. Rodriguez Avenue

Quezon City, Philippines

Telefax number: +632 723-0101 loc. 5210

E-mail address: lermahbunoy@yahoo.com
} 
Table 1. Thyroid function tests

\begin{tabular}{|c|c|c|c|c|c|c|}
\hline & \multicolumn{3}{|c|}{ Pre-operative Values } & \multicolumn{2}{|c|}{ Post-operative Values } & \multirow{2}{*}{$\begin{array}{c}\text { After } 8 \text { weeks of Methimazole } \\
\text { April } 2012\end{array}$} \\
\hline & Oct 19, 2010 & Oct 25,2010 & Nov 19, 2010 & Feb 2011 & Feb 2012 & \\
\hline $\mathrm{TSH}$ & $\begin{array}{l}14.15 \mathrm{ulU} / \mathrm{ml} \\
(0.4-4.5)\end{array}$ & $\begin{array}{l}14 \mathrm{ulU} / \mathrm{ml} \\
(0.4-4.5)\end{array}$ & $\begin{array}{c}4.084 \mathrm{ulU} / \mathrm{ml} \\
(0.49-4.64)\end{array}$ & $\begin{array}{l}6.4 \mathrm{ulU} / \mathrm{ml} \\
(0.35-5.5)\end{array}$ & --- & $\begin{array}{l}2.32 \mathrm{ulU} / \mathrm{ml} \\
(0.35-5 .)\end{array}$ \\
\hline FT4 & $\begin{array}{c}\mathrm{T} 4-259 \mathrm{nmol} / \mathrm{L} \\
(66-181)\end{array}$ & $\begin{array}{l}0.78 \mathrm{ng} / \mathrm{dl} \\
(0.8-1.8)\end{array}$ & $\begin{array}{l}2.7 \mathrm{ng} / \mathrm{dl} \\
(0.71-1.85)\end{array}$ & $\begin{array}{l}2.37 \mathrm{ng} / \mathrm{dl} \\
(0.89-1.76)\end{array}$ & $\begin{array}{l}2.26 \mathrm{ng} / \mathrm{dl} \\
(0.89-1.76)\end{array}$ & $\begin{array}{c}1.92 \mathrm{ng} / \mathrm{dl} \\
(0.89-1.76)\end{array}$ \\
\hline FT3 & $\begin{array}{c}\text { T3-5.99 pg/ml } \\
(1.30-3.10)\end{array}$ & $\begin{array}{l}1.35 \mathrm{pg} / \mathrm{ml} \\
(1.4-4.4)\end{array}$ & --- & $\begin{array}{l}7.46 \mathrm{pg} / \mathrm{ml} \\
(2.30-4.20)\end{array}$ & $\begin{array}{l}6.38 \mathrm{pg} / \mathrm{ml} \\
(2.30-4.20)\end{array}$ & $\begin{array}{l}5.84 \mathrm{pg} / \mathrm{ml} \\
(2.30-4.20)\end{array}$ \\
\hline
\end{tabular}

Table 2. Other laboratory results

\begin{tabular}{cc} 
Table 2. Other laboratory results & \\
\hline Test & Values \\
\hline ACTH & $\begin{array}{c}26.20 \mathrm{pg} / \mathrm{ml} \\
(5-56)\end{array}$ \\
& $2.8 \mathrm{ug} / \mathrm{dl}$ \\
cortisol & $1 \mathrm{mlU} / \mathrm{ml}$ \\
& $(1.4-7.7)$ \\
LH & $2 \mathrm{mlU} / \mathrm{ml}$ \\
& $(1.5-14)$ \\
FSH & $5.8 \mathrm{ng} / \mathrm{ml}$ \\
& $(2.5-17)$ \\
& $20.8 \mathrm{pg} / \mathrm{ml}$ \\
Prolactin (1:100 dilution) & $3.94 \mathrm{ug} / \mathrm{dl}$ \\
ACTH Stimulated Test & $10.52 \mathrm{ug} / \mathrm{dl}$ \\
ACTH & $13.27 \mathrm{ug} / \mathrm{dl}$ \\
Cortisol baseline & \\
$30 \mathrm{~min}$ &
\end{tabular}

Clinical examination revealed an ectomorphic male with diffuse enlargement of the thyroid gland but with no signs and symptoms of hyperthyroidism.. Vital signs revealed a BP: 120/70 mm Hg, HR: 72 bpm, RR: 16 cpm and BMI: $16.99 \mathrm{~kg} / \mathrm{m} 2$. Further endocrine work-ups revealed an inadequate adrenal reserve (Table 2); hence, he was started on Prednisone. The TSH, FT3 and FT4 were still elevated 6 weeks post-operatively (Table 1 ).

In the presence of elevated thyroid hormones, inappropriately high TSH and a pituitary macroadenoma with residual tumor after excision, a diagnosis of a TSHproducing Pituitary Adenoma was highly considered. Limited by the unavailability of alpha-subunit and TRH testing in our country, we only did immunohistochemical staining for $\mathrm{TSH}$, which showed a negative staining (Figure 2b). Excision of the residual mass was advised. The patient and his family have agreed to another surgery but are financially constrained. His repeat FT4 and FT3 levels were elevated. His repeat MRI 8 months post-operatively revealed unchanged size of the sellar-suprasellar mass measuring $3.76 \times 4.32 \mathrm{~cm}$ (Figure 4). Thyroid Scintigraphy revealed diffuse thyromegaly with high normal uptake (2hr and $24-\mathrm{hr}$ uptake at $11 \%$ and $41 \%$ respectively). The patient received methimazole, prednisone was continued and levetiracetam was discontinued, with no recurrence of seizure after discontinuation. Repeat thyroid function test 8 weeks after intake of methimazole showed improvement of his thyroid function tests. FT4 and FT3 were still elevated but lower than the previous test. TSH was inappropriately normal. At present, the patient remains clinically asymptomatic except for the visual field deficit.

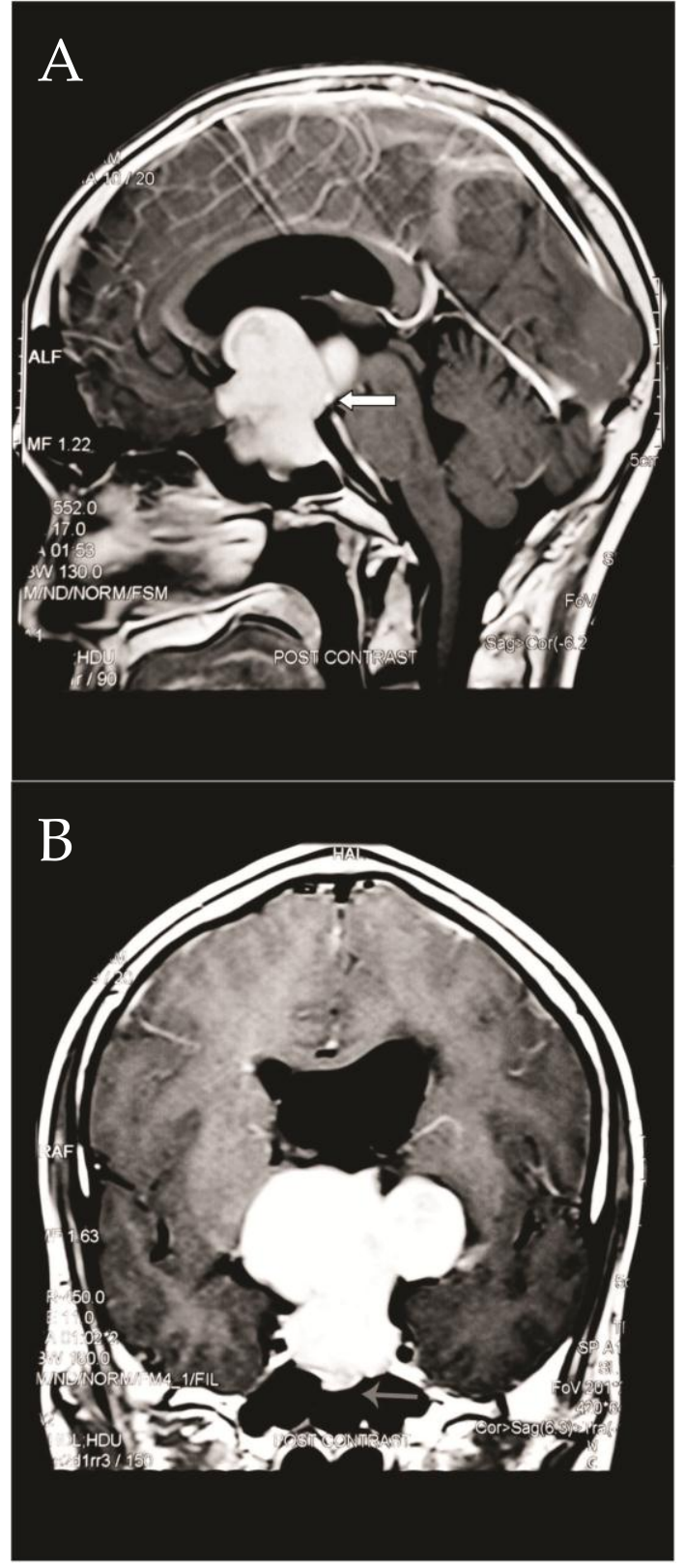

Figure 1. Preoperative contrast-enhanced MRI showing an enhancing lobulated sellar-suprasellar mass, $4 \times 5 \times 4.5 \mathrm{~cm}$ (APxTxL), abutting the third ventricle $(1 \mathrm{a}$, arrow) and bulging inferiorly into the sphenoid sinus ( $1 \mathrm{~b}$, arrow) 


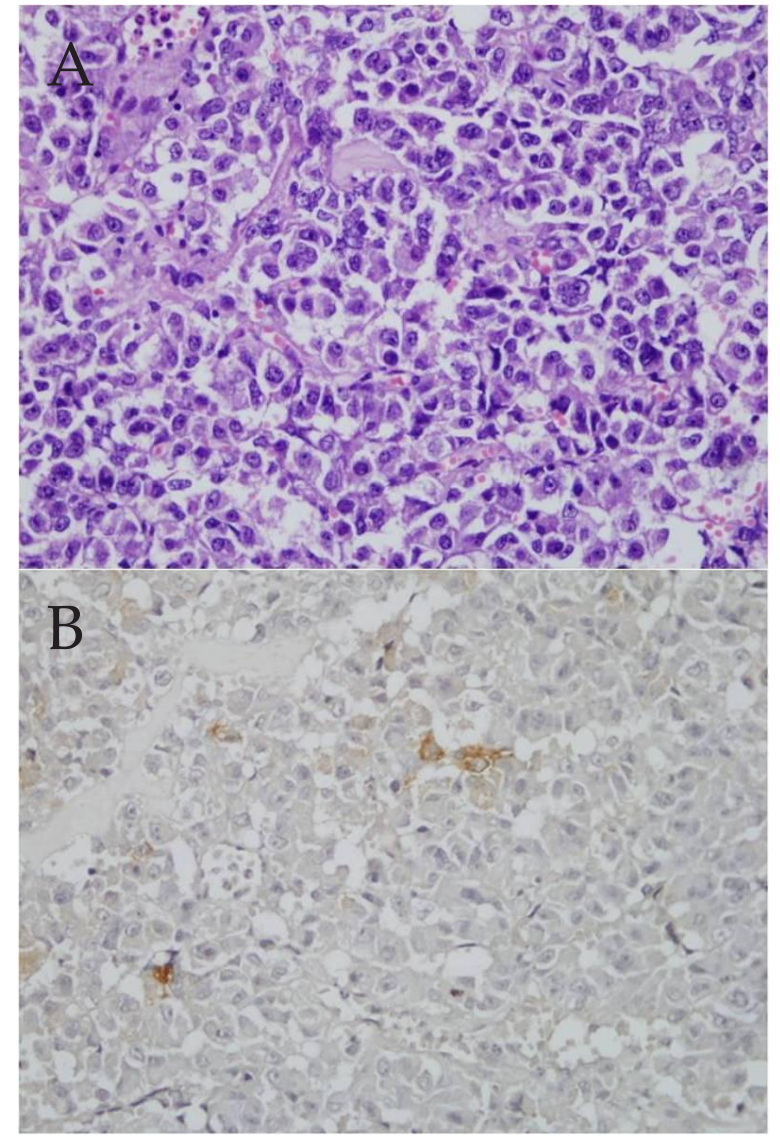

Figure 2. Pituitary adenoma. (a) Microscopic examination showing monotonous population of cells with round nuclei, prominent nucleoli and eosinophilic cytoplasm, with no mitotic figures seen (H\&E, x40). (b) Immunohistochemical staining showing negative reaction for TSH (x40).

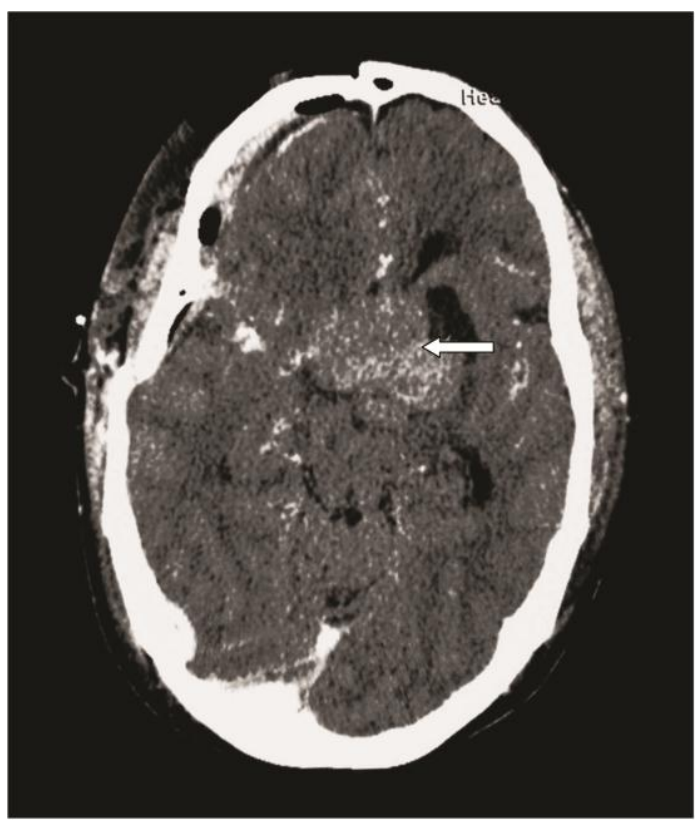

Figure 3. Post-operative contrast-enhanced CT showing the partially excised large sellar-suprasellar mass, $3.1 \times 4.4 \times 3 \mathrm{~cm}(\mathrm{APxT} \times C C)$
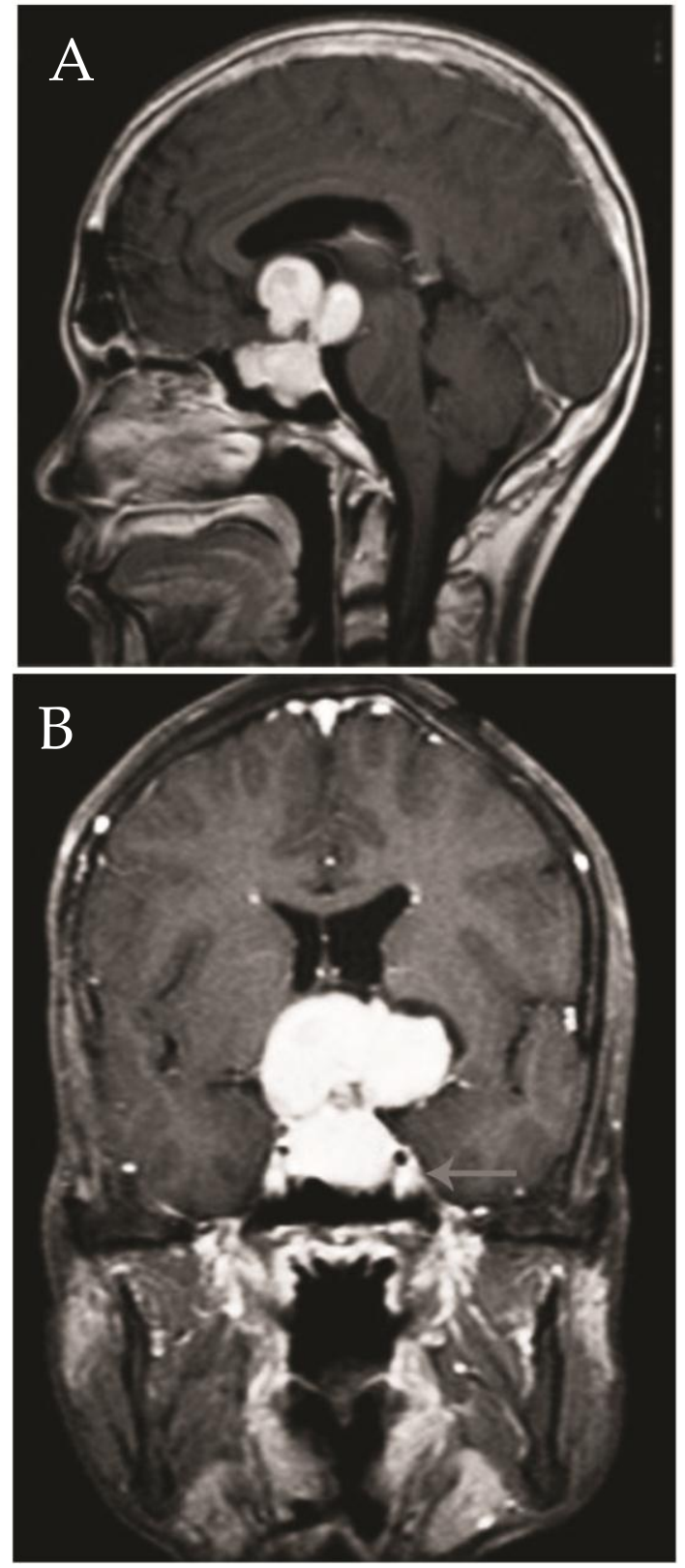

Figure 4. Contrast-enhanced MRI 8 months postoperatively showing unchanged size of the large sellar-suprasellar mass, $3.76 \times 4.34 \mathrm{~cm}$, with similar degree of mass effect and probable invasion to the left cavernous sinus ( $3 b$, arrow)

\section{Discussion}

TSH-producing pituitary tumors are rare, accounting for less than $1 \%$ of all cases of hyperthyroidism and $1 \%$ of all functioning pituitary tumors. ${ }^{1}$ They secrete biologically active thyrotropin in an autonomous fashion. ${ }^{2}$ They are usually large, $88 \%$ are macroadenomas and more than $60 \%$ are locally invasive. Distant metastases are extremely rare. ${ }^{3}$. TSHomas are usually macroadenomas at the time of presentation due to delay in diagnosis. ${ }^{4}$ They can be associated with secretion of GH in $15 \%$, prolactin in $10 \%$ and rarely with gonadotrophins. ${ }^{5}$ Most patients have the typical symptoms and signs of hyperthyroidism (56\% severe and $36 \%$ moderate), but a few patients have had 
mild or even no symptoms in $12 \% .{ }^{6}$ Other clinical features include a diffuse goiter in $95 \%$, visual field defect in $40 \%$, menstrual disturbances in $30 \%$ and galactorrhea, with or without co-secretion of prolactin in 30\%. ${ }^{2}$ Thyrotoxic symptoms and signs were absent in our case, except for the diffuse thyromegaly. Likewise, our patient presented with visual field defects and panhypopituitarism as evidence of tumor growth and mass effect.

The presence of high serum $\mathrm{T} 4$ and T3, high or inappropriately normal TSH together with anatomic evidence of a pituitary tumor by MRI strongly confirmed the diagnosis of a TSHoma. Other tests include an elevated $\alpha$-subunit of glycoprotein hormones, which is seen in $85 \%$, and an elevated $\alpha$-subunit: TSH molar ratio. Because $\alpha$ subunit is co-secreted with TSH from the pituitary gland, elevated levels are suggestive of a TSHoma.

Two rare but important causes of inappropriate secretion of TSH are TSHomas and resistance to thyroid hormone (RTH). ${ }^{7}$ It is important to distinguish the two because it can pose diagnostic and therapeutic dilemmas. Delayed diagnosis of TSHomas can lead to tumor growth and poor surgical cure rates, whereas medical, surgical or radioablative treatments in patients with resistance to thyroid hormone are usually unnecessary and potentially harmful. In TSHomas, the serum sex hormone-binding globulin concentration (SHBG) is high, whereas is normal in RTH. The serum $\alpha$-subunit concentration is normal in RTH but, as noted, often high in patients with TSHomas. The serum TSH concentration increases in response to TRH in patients with RTH, but not in most patients with TSHomas. Patients with RTH are more likely to have a fall in serum TSH concentrations in response to T3. ${ }^{2,5}$ In the Philippine setting, distinguishing the two is very difficult due to unavailability of some diagnostic tools like $\alpha$ subunit and TRH.

The presence of a pituitary adenoma on MRI or CT supports the diagnosis of TSHoma, however, it was found out that $10 \%$ of the normal population can have pituitary incidentaloma ${ }^{8}$ hence, the possibility of co-existing RTH. Unlike patients with TSHomas, patients with RTH do not have symptoms of pituitary enlargement. ${ }^{9}$ Reported cases of TSHomas have been macroadenomas in 90\%. ${ }^{10}$ Our patient has a pituitary macroadenoma associated with symptoms of pituitary enlargement.

In this case, the presence of persistently elevated free hormones and unsuppressed TSH, together with a pituitary macroadenoma and tumor residual after surgical excision are strongly suggestive of a TSH-producing adenoma.

TSHomas exhibit positive immunostaining for $\alpha$-subunit and TSH- $\beta$ in $20 \%$ to $75 \%$ of cells. ${ }^{3}$ In our case, staining was negative. This may be due to low TSH concentration in the adenomatous tissue ${ }^{11}$ as could be explained by the relatively low peripheral TSH levels in the presence of a large adenomatous mass. ${ }^{12}$ Also, it could be that masked antigen determinants on the surface of the adenomatous cells account for the negative TSH staining. ${ }^{12}$

Surgery has been recommended as first-line treatment, but surgical cures occur in fewer than $40 \%$ of patients. ${ }^{3}$ More than half of the patients exhibit evidence of residual tumor when assessed by MRI at 6 months after surgery. ${ }^{13}$ Radiation has mostly been employed as adjunctive therapy to surgery, especially when the latter was not curative. Octreotide, a somatostatin analogue, used as either primary or adjunctive treatment, suppresses TSH in $90 \%$ of patients and reduces tumor size in $50 \% .^{14}$ Propranolol, thyroid ablation with radioactive iodine, thyroidectomy, anti-thyroid medications including methimazole and propylthiouracil, are employed. However, with all these treatment modalities, no single treatment is expected to cure patients with TSHomas. ${ }^{3}$

It is important to assess the degree of hyperthyroidism to determine whether control of these signs and symptoms should be undertaken before further evaluation or treatment of the pituitary tumor to avoid perioperative death. Our patient had an uneventful perioperative course, and this may be because he is clinically euthyroid.

\section{Conclusion}

In the case we have described, the findings from the available laboratory, radiological investigations and clinical course were consistent with the diagnosis of a TSHoma. Unlike most patients with TSHomas, our patient was relatively asymptomatic, had mild biochemical hyperthyroidism, although with a large tumor residual. Since the patient is not able to afford a second surgery, we elected to continue close clinical, biochemical and radiologic monitoring as per current recommendations.

\section{Learning points}

Clinicians should keep an eye out for these rare entities. Discordant thyroid function tests in the presence of a pituitary adenoma should be interpreted with caution so as not to miss this rare kind of case. Since diagnosis is usually delayed and management is limited, early detection is essential.

In patients presenting with chronic headache and blurring of vision, it is important to do complete neurological and visual field examination to avoid missing out the possibility of pituitary tumors and its complications. In the presence of pituitary tumors or incidentaloma, with or without symptoms, it is recommended that patients should undergo clinical and laboratory evaluations for evidence of hypopituitarism and hormone hypersecretion. 


\section{References}

1. Gesundheit N, Petrick PA, Nissim M, et al. Thyrotropin-secreting pituitary adenomas: Clinical and biochemical heterogeneity. Case reports and follow-up of nine patients. Ann Intern Med 1989; 111:827.

2. Thyrotropin (TSH)-secreting pituitary adenomas. http://www. uptodate.com/store. Accessed March 26, 2012.

3. Melmed S, Kleinberg D. Pituitary masses and tumors. Williams Textbook of Endocrinology, 12 ${ }^{\text {th }}$ ed. 2011.

4. Wass JAH, Shalet SM, Oxford Textbook of Endocrinology and Diabetes.1st Ed. New York; Oxford University Press; 2002.p. 312.

5. Beck-Peccoz P, Brucker-Davis F, Persani L, et al. Thyrotropin secreting pituitary tumors. Endocr Rev 1996; 17:610-638.

6. Brucker-Davis F, Oldfield EH, Skarulis MC, et al. Thyrotropin secreting pituitary tumors: Diagnostic criteria, thyroid hormone sensitivity and treatment outcome in 25 patients followed at the National Institutes of Health. J Clin Endocrinol Metab 1999; 84:476.

7. Faglia G, Beck-Peccoz P, Piscitelli G, et al. Inappropriate secretion of thyrotropin by the pituitary. Horm Res 1987; 26:79-99.

8. Molitch M, Russell E. The pituitary incidentaloma. Ann Intern Med 1990; 112:925.

9. Mc Dertmott MT, Ridgway EC. Central hyperthyroidism. Endocrine Metab Clin North Am 1998; 27:187-201.

10. Beck-Peccoz P, Persani L, Mantovani S, et al. Thyrotropin-secreting pituitary adenomas. Metabolism 1996; 45: 75-79.

11. Koide $\mathrm{Y}$, Kugai $\mathrm{N}$, Kimura S, Fujita $\mathrm{T}$, et al. A case of pituitary adenoma with possible simultaneous secretion of thyrotropin and follicle stimulating hormone. J Clin Endocrinol Metab. 1982; 54: 397403.

12. Savastano S, Lombardi G, Merola B, et al. Hyperthyroidism due to a thyroid-stimulating hormone (TSH)-secreting pituitary adenoma associated with functional hyperprolactinaemia. Acta Endocrinologica 1987116 452-458.

13. Losa M, Giovanelli M, Persani L, et al. Criteria of cure and follow-up of central hyperthyroidism due to thyrotropin-secreting pituitary adenomas. J Clin Endocrinol Metab. 1996; 81:3084-3090.

14. Colao A, Pivonello R, Di Somma C, et al. Medical therapy of pituitary adenomas: Effects on tumor shrinkage. Rev Endocr Metab Disord. 2009; 10:111-123.

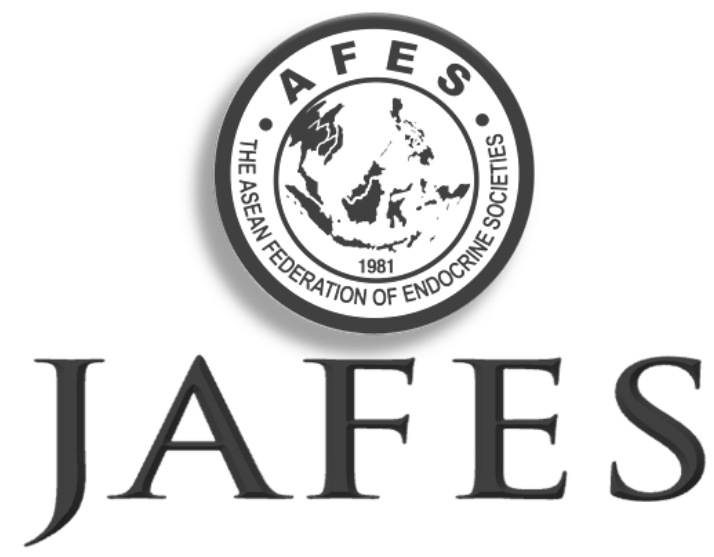

\section{Clinical controversies and disease updates are also welcome. Instructions to Authors available at www.ASEAN-endocrinejournal.org.}

